\title{
ВмJ Global Health Are asylum seekers, refugees and foreign migrants considered in the COVID-19 vaccine discourse?
}

\author{
Ferdinand C Mukumbang
}

To cite: Mukumbang FC. Are asylum seekers, refugees and foreign migrants considered in the COVID-19 vaccine discourse?BMJ Global Health 2020;5:e004085. doi:10.1136/ bmjgh-2020-004085

Handling editor Seye Abimbola

Received 29 September 2020 Revised 16 October 2020 Accepted 17 October 2020

\section{Check for updates}

(c) Author(s) (or their employer(s)) 2020. Re-use permitted under CC BY-NC. No commercial re-use. See rights and permissions. Published by BMJ.

School of Public Health University of the Western Cape, Cape Town, South Africa

Correspondence to Dr Ferdinand C Mukumbang; mukumbang@gmail.com

\section{INTRODUCTION}

There is a propitious belief that a potent vaccine against the SARS-COV-2 virus is a panacea for the COVID-19 pandemic. The need for a potent vaccine is heightened as many nations are finding it counterproductive to sustain national lockdowns and individuals are becoming complacent with their hygiene and social (physical) distancing practices. Currently, there are more than 100 COVID-19 vaccine candidates under development, with a number of these in the human trial phase. It is suggested that the introduction of a COVID-19 vaccine will prevent the loss of US $\$ 375$ billion to the global economy every month. ${ }^{1}$ There is a scientific consensus that the only way toeradicate the pandemic will be to vaccinate all people worldwide. ${ }^{2}$ To this end, the United Nations General Assembly calls for "the rapid scaling up of manufacturing and establishment of supply chains that promote and ensure fair, transparent, equitable, efficient and timely access to drugs and future COVID-19 vaccines'. ${ }^{3}$ Consequently, at this moment, global health and political discourse related to the COVID-19 pandemic are dominated by COVID-19 vaccine development, production and distribution.

Regarding the vaccine distribution, there are many proposals on the table for the ethical distribution between countries. ${ }^{4}$ There is a continuum of positions regarding the acquisition of COVID-19 vaccines. To one extreme is vaccine nationalism, whereby governments sign agreements with pharmaceutical manufacturers to supply their populations with vaccines ahead of the vaccines becoming available for other countries. ${ }^{5}$ On the other extreme is the global access to COVID-19 vaccine through fair distribution underpinned by the notion of global public good-impacting residents of more than one country, even if not necessarily the whole world. ${ }^{6}$ Many countries display a mix of
Summary box

As the world struggles to contain the COVID-19 pandemic, different countries are increasingly focused on the protection of their citizens and are neglecting their obligations and commitments to protecting asylum seekers, refugees and foreign-born migrants living within their borders.

The vulnerabilities of asylum seekers, refugees and foreign-born migrants have exacerbated during the COVID-19 pandemic, consequently, they are more likely to suffer the physical and mental health and socioeconomic consequences of COVID-19. Such disproportionate impact warrants them to be considered a most-at-risk population.

- Structures and mechanisms and migrant-aware policies should be put in place both globally and within different countries to ensure that this population is not left behind in the COVID-19 vaccine narratives and considerations.

- We argue that countries that get COVID-19 Vaccines Global Access (COVAX) vaccines should also explicitly include asylum seekers and refugees in their 'atrisk populations', to get the vaccines.

- Also, the International Organization for Migration and civil society organisations such as Médecins sans Frontières should get sufficient COVAX vaccines and establish mechanisms to ensure the timely vaccination of this population.

both, first trying to secure vaccines for their populations but also doing their share in terms of helping to ensure that vaccines are available to the most vulnerable everywhere. The Access to COVID-19 Tools Accelerator, a global collaboration, seeks to accelerate the development, production and equitable access to COVID-19 tests, treatments and vaccines, ${ }^{1}$ with the vaccine pillar being managed through the COVID-19 Vaccines Global Access (COVAX) Facility. Through the COVAX platform, countries are encouraged to sign up to a deal that will ensure that they receive a portion of the anticipated 2 
billion doses of vaccines that will be available by the end of 2021

According to the WHO's COVID-19 vaccine allocation mechanisms document, access to a vaccine at its inception would be aimed at protecting healthcare workers and the most-at-risk in a bid to mitigate the public health and economic impacts of the pandemic. ${ }^{1}$ The general COVID-19 literature has consistently identified people with chronic comorbidities as a most-at-risk population, while the literature on migration in the context of COVID-19 has also identified asylum seekers, refugees and foreign migrants as a most-at-risk population owing to their existing vulnerabilities. ${ }^{78}$ Worst still, asylum seekers, refugees and foreign-born migrants are most likely to suffer from the consequences of COVID-19 as their conditions continue to worsen in refugee camps around the world, ${ }^{9}$ thus increasing their risk.

The understanding on how COVAX works is that the WHO will develop a framework through which the COVAX Facility will ensure the equitable distribution of the COVID-19 vaccine doses to help protect the most-atrisk-greater chances of being infected with COVID-19 or of getting very sick-groups in all participating countries. In this way, it is understood that healthcare workers and older citizens and people living with comorbidities will be given priority. The question, therefore, is to what extent will asylum seekers, refugees and foreign migrants who through their increased vulnerabilities and potential of being impacted by COVID-19 be considered as a mostat-risk population, thus prioritised for vaccination?

\section{CENTRAL ARGUMENT}

With the number of COVID-19-related deaths reaching the 1 million mark and affecting every geographical region globally, the COVID-19 vaccine must be treated as a global public good..$^{10}$ Nevertheless, as the world struggles to contain COVID-19, different countries are increasingly focused on the protection of their citizens and are neglecting their obligations and commitments to protect asylum seekers, refugees and foreign-born migrants living within their borders. For instance, although countries like England considered accommodating unsuccessful asylum seekers at the start of the COVID-19 pandemic, these unsuccessful asylum seekers where being evicted from their Home Office provided accommodations during the second wave of the COVID-19 pandemic, an act which makes no sense in either humanitarian or public health terms. ${ }^{11}$ Also, despite international maritime laws dictating a 'duty to rescue' refugees and asylum seekers in distress at sea, search-rescue-disembarkation operations in the Mediterranean have been brought to a halt. ${ }^{12}$ These structural xenophobic tendencies, and more, are further manifested in the lack of engagement and consideration of this population in countries' economic, poverty and hunger alleviation schemes during the national lockdown measures. ${ }^{7}$
Although COVID-19, disproportionately, has a greater impact on certain populations, asylum seekers, refugees and foreign-born migrants usually find themselves in comparatively worse positions of vulnerability. ${ }^{7}$ The COVID-19 vulnerabilities are usually an extrapolation of already existing vulnerabilities: weakened social support structures, bleak socioeconomic prospects, unequal access to healthcare and social services, precarious housing conditions, tenuous living and working conditions, and higher risks of exploitation and abuse. ${ }^{813} 14$ These vulnerabilities have exacerbated in the context of the COVID-19 pandemic as they are living in crowded refugee camps and deportation centres with little or no resources and opportunities to practise personal hygiene and social (physical) distancing, in addition to diminished access to food and healthcare services. ${ }^{71516}$ Those among the general population live in informal/illegal situations in urban slums having issues with access to basic health facilities owing to insecurity and crime that prevail in these informal settlements.

A few countries have taken steps to accommodate asylum seekers and refugees at the start of the COVID-19 pandemic. For instance, Portugal temporarily granted all asylum seekers and foreign-born migrants full citizenship rights to remove the structural barriers to access to healthcare services. ${ }^{17}$ In Germany, the COVID-19 pandemic acted as a catalyst to mobilise solidarity and support for the plight of refugees. ${ }^{18}$ In England, the thousands of asylum seekers who were refused were provided with accommodation by the Home Office at the start of the COVID-19 outbreak. ${ }^{11}$ Nevertheless, many other countries have persisted with policies that exclude asylum seekers, refugees and foreign-born migrants from critical services while also continuing with deportations during the worldwide travel bans. ${ }^{717}$

Based on the way asylum seekers, refugees and foreignborn migrants were treated during the national lockdown implemented to curb the spread of the pandemic, there is little chance that this population will be considered for immunisation when the vaccine reaches the borders of various countries. Reflecting on this in light of ongoing discourse on the political stakes of migration governance, in South Africa for instance, we observe that the COVID-19 response revealed little change in the government's agenda to deal with asylum seekers, refugees and other migrants. ${ }^{19}$ This reticence to include asylum seekers, refugees and foreign migrants in policies and mechanisms to address the COVID-19 pandemic is further fuelled by xenophobic tendencies. ${ }^{79}$ According to Reidy, ${ }^{17}$ some governments are likely to take advantage of the COVID-19 crisis to push through legally dubious, hardline migration policies that cannot be justified by public health concerns. The glaring absence of migrationaware and mobility-competent policies is likely going to reduce the level of engagement of asylum seekers, refugees and foreign migrants in the national fight against the COVID-19 pandemic and thus reducing their consideration for a COVID-19 vaccine. 
At the global level, currently, COVAX envisages setting aside a small buffer of about $5 \%$ of the total number of available doses that will be reserved to build a stockpile to help with acute outbreaks and to support humanitarian organisations, for example, to vaccinate refugees who may not otherwise have access. ${ }^{20}$ The WHO EURO outlines current best practice, evidence and knowledge to support policy and programme development for the vaccination of refugees and migrants, ${ }^{21}$ which could be used to guarantee COVID-19 vaccine coverage in this population group. Unfortunately, these bestpractices and policies have not been dependably considered. We, therefore, concur with Severoni and Bartovic ${ }^{22}$ that future efforts need to build on existing structures and resources to bolster coordination and prepare a blueprint for future emergency vaccine distribution in a manner that considers asylum seekers, refugees and migrants equitably.

The International Organization for Migration and civil society organisations (CSO) are strategically placed to contribute to discussions and decisions around the scale-up and equitable access to COVID-19 vaccines especially representing the interests of asylum seekers, refugees and foreign migrants. Nevertheless, it appears their representation and engagement in the structure and processes of Gavi-the Coalition for Epidemic Preparedness Innovations-is based on Gavi's inadequate appreciation and distrust of what CSOs do and can bring to Gavi's operations. ${ }^{23}$ Owing to pressure from CSOs, Gavi and WHO are seeking representative CSOs to participate in COVAX. ${ }^{24}$ If CSOs are better represented in the COVAX governance mechanism, there is a chance that they will be better placed to represent the interests of asylum seekers, refugees and foreign migrants efficiently.

Although governments will be the initial recipients of the COVID-19 vaccines, fair distribution within each country must reflect a moral concern for the ultimate recipients and should be guided by the following three principles: (1) benefiting people and limiting harm, (2) prioritising the disadvantaged, and (3) equal moral concern. ${ }^{25}$ This 'fair priority model', proposed by Emanuel et $a l^{25}$ accommodates asylum seekers, refugees and foreign migrants more explicitly as it prioritises the disadvantaged. In this approach, Emanuel et $a l^{25}$ propose that a fair allocation of the COVID-19 vaccine requires distributing the first doses to those population segments where it is possible to save the greatest number of life years, then considering also the disability that can be prevented by the vaccine and the amount of poverty and aggregate economic damage the vaccine can prevent, and finally distributing the vaccine to reduce transmission rates as far as possible. A truly ethical proposal toward the COVID-19 vaccine distribution should accommodate asylum seekers, refugees and foreign migrants, treating all people equally and helping them get vaccines when they cannot do so on their own. This position is contrary to the notion of accepting inequality in access as an unchangeable fact; bypassing the poor to help the rich, the vulnerable to help the strong. ${ }^{4}$

At this stage, there is the recognition that the first useful vaccines to emerge may be in short supply, and approved vaccines will initially be made available to a tightly targeted $3 \%$ of the population of COVAX participating countries, then building over time to $20 \%$ of each country's most vulnerable population. ${ }^{26}$ While decisions on the distribution of vaccines initially supplied under the COVAX scheme will remain at each nation's discretion, countries are advised that they should use the initial 3\% of their vaccines to focus initially on reducing mortality and protecting the health system-vaccinating healthcare and social workers. ${ }^{26}$ In the same way, the other $20 \%$ of the vaccines allocated for the country's most vulnerable population will be at the discretion of the country to manage. After everybody has received the $20 \%$, the vaccine would be distributed according to other criteria, such as country vulnerability and the immediate threat of COVID- $19 .{ }^{20}$ Although it is often politically untenable to consider refugees and asylum seekers when it comes to the planning of vaccination campaigns of this nature, ${ }^{22}$ following this proposed distribution protocol, we argue that asylum seekers, refugees and foreign migrants should be considered during the $20 \%$ distribution point as they fit the bill of a vulnerable population. The point is that there is a need to include and prioritise refugees, asylum seekers and foreign migrants in all COVID-19 vaccination programmes, regardless the source of the vaccine, to successfully eliminate the pandemic within the national borders and indeed globally.

\section{CONCLUSION}

Whether COVID-19 vaccines are obtained through equitable distribution to all participating countries or through vaccine nationalism, it is unclear what policies, principles and mechanisms are in place to ensure that asylum seekers, refugees and foreign migrants are not left behind even though they are a vulnerable population. The call, therefore, is for advocacy groups and international organisations working with asylum seekers, refugees and foreign migrants to advocate for this group of people not to be left behind in the fight against the COVID-19 pandemic. The COVID-19 vaccine offers CSOs, international bodies and various governments an opportunity to reform and address some critical questions about access to COVID-19 vaccines for asylum seekers, refugees and foreign migrants.

Acknowledgements The author acknowledges the huge contributions through the review comments made by Kristof Decoster and Professor Wim van Damme in the developing manuscripts.

Contributors FCM contributed to all aspects of the manuscript.

Funding The authors have not declared a specific grant for this research from any funding agency in the public, commercial or not-for-profit sectors.

Competing interests None declared.

Patient consent for publication Not required.

Provenance and peer review Not commissioned; externally peer reviewed. 
Data availability statement There is no data in this work.

Open access This is an open access article distributed in accordance with the Creative Commons Attribution Non Commercial (CC BY-NC 4.0) license, which permits others to distribute, remix, adapt, build upon this work non-commercially, and license their derivative works on different terms, provided the original work is properly cited, appropriate credit is given, any changes made indicated, and the use is non-commercial. See: http://creativecommons.org/licenses/by-nc/4.0/.

ORCID iD

Ferdinand C Mukumbang http://orcid.org/0000-0003-1441-2172

\section{REFERENCES}

1 Gavi. COVAX facility, 2020. Available: https://www.gavi.org/covaxfacility [Accessed 25 Sep 2020].

2 Yunus M, Donaldson C, Perron J-L. COVID-19 vaccines a global common good. The Lancet Healthy Longevity 2020;1:e6-8.

3 The United Nations General Assembly. International cooperation to ensure global access to medicines, vaccines and medical equipment to face COVID-19, 2020.

4 Hassoun N. How to distribute a COVID-19 vaccine ethically scientific american. policy \& ethics, 2020. Available: https://www. scientificamerican.com/article/how-to-distribute-a-covid-19vaccine-ethically/ [Accessed 27 Sep 2020].

5 Kamradt-Scott A. Why 'vaccine nationalism' could doom plan for global access to a COVID-19 vaccine, 2020. Available: https:// theconversation.com/why-vaccine-nationalism-could-doom-planfor-global-access-to-a-covid-19-vaccine-145056 [Accessed 26 Sep 2020].

6 Love J. The use and abuse of the phrase "global public good" | global policy journal, 2020. Available: https://www. globalpolicyjournal.com/blog/28/09/2020/use-and-abuse-phraseglobal-public-good [Accessed 28 Sep 2020]

7 Mukumbang FC, Ambe AN, Adebiyi BO. Unspoken inequality: how COVID-19 has exacerbated existing vulnerabilities of asylumseekers, refugees, and undocumented migrants in South Africa. Int $J$ Equity Health 2020;19:1-7.

8 Virupaksha HG, Kumar A, Nirmala BP. Migration and mental health: an interface. J Nat Sci Biol Med 2014:5:233-9.

9 Chulov M. Aid agencies warn of Covid-19 crisis in refugee camps as winter approaches | global development | the guardian, 2020. Available: https://www.theguardian.com/global-development/2020/ sep/23/aid-agencies-warn-of-covid-19-crisis-in-refugee-camps-aswinter-approaches [Accessed 27 Sept 2020].

10 Smith-Spark L. Global Covid-19 deaths pass 1 million. Experts fear the toll may double before a vaccine is ready - CNN, 2020. Available: https://edition.cnn.com/2020/09/28/health/coronavirus-millionglobal-deaths-int//index.html [Accessed 29 Sept 2020]

11 Taylor D. Home office urged to halt evictions of refused asylum seekers | immigration and asylum | the guardian, 2020. Available: https://www.theguardian.com/uk-news/2020/oct/07/home-office- urged-to-halt-evictions-of-refused-asylum-seekers [Accessed 8 Oct 2020].

12 Chugh A. How COVID-19 might change migration rhetoric and policy | world economic forum, 2020. Available: https://www.weforum.org/ agenda/2020/05/covid-19-coronavirus-migration-migrant-workersimmigration-policy-health-securitization-risk-travel-bubbles/ [Accessed 8 Oct 2020].

13 Vearey J, Modisenyane M, Hunter-Adams J. Towards a migrationaware health system in South Africa: a strategic opportunity to address health inequity. South African Health Review, 2017: 89-98.

14 Merry L, Pelaez S, Edwards NC. Refugees, asylum-seekers and undocumented migrants and the experience of parenthood: a synthesis of the qualitative literature. Global Health 2017;13:1-17.

15 United Nations. COVID-19 and people on the move, 2020. Available: https://www.un.org/sites/un2.un.org/files/sg_policy_brief_on people_on_the_move.pdf [Accessed 22 Jul 2020].

16 Choudhari R. COVID 19 pandemic: mental health challenges of internal migrant workers of India. Asian J Psychiatr 2020;54:102254.

17 Reidy E. How COVID-19 is being exploited to harden migration policies. the new humanitarian, 2020. Available: https://www. thenewhumanitarian.org/analysis/2020/04/17/coronavirus-globalmigration-policies-exploited [Accessed 25 Sep 2020]

18 Kelerstein A. COVID-19 and the transmission of vulnerability. refugee law initiative, 2020. Available: https://rli.blogs.sas.ac.uk/2020/05/01/ covid-19-and-the-transmission-of-vulnerability/ [Accessed 26 Sep 2020].

19 Zanker FL, Moyo K. The corona virus and migration governance in South Africa: business as usual? Analysis and Report 2020.

20 Bailey D. Coronavirus: who would get the vaccine first? - BBC News, 2020. Available: https://www.bbc.com/news/health-54027269 [Accessed 28 Sep 2020].

21 World Health Organization. Delivery of immunization services for refugees and migrants. Copenhagen, 2019.

22 Severoni S, Bartovic J. Equitable access to covid-19 vaccine for all must include refugees and migrants - The BMJ, 2020. Available: https://blogs.bmj.com/bmj/2020/05/19/equitable-access-to-covid19-vaccine-for-all-must-include-refugees-and-migrants/ [Accessed 16 Oct 2020].

23 Patnaik P. Gavi's discomfort with civil society on vaccines - geneva health files, 2020. Available: https://genevahealthfiles.wordpress. com/2020/09/24/gavi-civil-society-unhappy-engagement/ [Accessed 28 Sep 2020].

24 World Health Organization. COVAX seeks civil society representatives to contribute to ensuring equitable global access to COVID-19 vaccines, 2010. Available: https://www.who.int/newsroom/articles-detail/covax-seeks-civil-society-representativesto-contribute-to-ensuring-equitable-global-access-to-covid-19vaccines [Accessed 26 Sep 2020].

25 Emanuel EJ, Persad G, Kern A, et al. An ethical framework for global vaccine allocation. Science 2020;369:1309-12

26 Beaumont P. 'Landmark moment': 156 countries agree to Covid vaccine allocation deal | Global development | The Guardian, 2020. Available: https://www.theguardian.com/global-development/2020/ sep/21/landmark-moment-156-countries-agree-to-covid-vaccineallocation-deal [Accessed 27 Sep 2020]. 